\title{
Growth and regression of ovarian follicles during the follicular phase of the oestrous cycle in heifers undergoing spontaneous and PGF-2 $\alpha$-induced luteolysis
}

\author{
S. M. Quirk, G. J. Hickey and J. E. Fortune \\ Section of Physiology in the Division of Biological Sciences and Department of Physiology in the \\ College of Veterinary Medicine, Cornell University, Ithaca, NY 14853, U.S.A.
}

\begin{abstract}
Summary. Ultrasonography was used to monitor the growth, ovulation and regression of individual ovarian follicles $\geq 5 \mathrm{~mm}$ during the late luteal and follicular phases of the oestrous cycle in heifers treated with injections of PGF- $2 \alpha$ to induce luteolysis and in heifers undergoing spontaneous luteolysis. Six heifers were given a single injection of PGF- $2 \alpha$ between Day 12 and 15 of the oestrous cycle and their ovaries were examined daily by transrectal ultrasonography until ovulation occurred. Another group of 5 heifers was examined daily by ultrasound from Day 14 or 15 of the cycle through spontaneous luteolysis and ovulation. Blood samples were taken twice daily from this group and analysed for progesterone to determine when luteolysis occurred. All heifers were checked for oestrous behaviour twice daily. Mean diameters of ovulatory follicles on each of the 3 days before oestrus were not different between PGF- $2 \alpha$-treated and untreated heifers. In both groups there was large variation among heifers in the sizes and growth rates of the ovulatory follicles. At 3 days before oestrus the diameters of ovulatory follicles were between 7.5 and $11 \mathrm{~mm}$ in PGF-2 $\alpha$-treated heifers and between 6 and $11.5 \mathrm{~mm}$ in untreated heifers. Non-ovulatory follicles decreased in size during the 3 days before oestrus and the number of non-ovulatory follicles within the size ranges of ovulatory follicles decreased. The ovulatory follicle was not consistently the largest follicle on the ovaries until the day of oestrus but was always one of the 2 largest follicles during the 3 days before oestrus. These results show that (1) there was variability among heifers in the size of the ovulatory follicle at various times before oestrus, (2) size alone was not a reliable predictor of the ovulatory follicle until the day of oestrus and (3) follicle dynamics during the 3 days before oestrus were similar in heifers undergoing spontaneous and PGF- $2 \alpha$-induced luteolysis.
\end{abstract}

\section{Introduction}

The dynamics of preovulatory follicular growth in cattle have been characterized only partially. Dufour, Whitmore, Ginther \& Casida (1972) labelled individual follicles with ink and found that the preovulatory follicle was the largest follicle present during the 3 days before oestrus, whereas before that time the preovulatory follicle was not the largest present. A later study demonstrated that turnover of large follicles and the growth of medium-sized follicles were more rapid at the end of the oestrous cycle (after Day 13) than at the beginning, and that follicles $<5 \mathrm{~mm}$ were capable of developing to ovulatory size within several days (Matton, Adelakoun, Couture \& Dufour, 1981). The aim of the present study was to characterize more completely follicular dynamics during the late luteal and follicular phases of the oestrous cycle by ultrasound imaging. Linear array ultrasound instruments which produce 'real-time', brightness mode images and which can be used 
transrectally in cattle and horses are now available (Palmer \& Driancourt, 1980; Reeves, Rantanen \& Hauser, 1984; Pierson \& Ginther, 1984; Ginther \& Pierson, 1984). These instruments produce moving, cross-sectional images of the reproductive tract as the transducer is moved along the rectal wall. Tissues of highest density are most 'echogenic' and appear brighter in ultrasound images, whereas tissues of lower density appear darker. Thus, corpora lutea are dense, grey, circumscribed areas and antral follicles are black spheres within the ovarian stroma. In the present study the ovaries of heifers undergoing spontaneous or prostaglandin (PG) F-2 $\alpha$-induced luteolysis were examined daily from the late luteal phase of the oestrous cycle through ovulation. The specific aims were to (1) determine the size of the ovulatory follicle at various times before oestrus, (2) characterize the patterns of growth and regression of non-ovulatory follicles in relation to the ovulatory follicles, and (3) compare follicular dynamics in heifers undergoing spontaneous and PGF- $2 \alpha$-induced regression of the corpus luteum.

\section{Materials and Methods}

Ultrasound examinations. Ultrasound examinations were made with a Technicare (Pitman-Moore, Washington Crossing, NJ, U.S.A.) 210DX portable linear array scanner with a $5 \mathrm{MHz}$ transducer designed for transrectal examinations in cattle and horses. Output from the ultrasound unit was recorded on videotape at each examination. Lidocaine hydrochloride $(2 \%)$ was used as an epidural anaesthetic before rectal manipulation to decrease contractions of the rectum. Faeces were removed from the rectum and each ovary was scanned several times by moving the transducer in a medial direction across the surface of the ovary. Ovaries were scanned in two planes whenever possible since scanning one surface of the ovary did not always permit visualization of all of the follicles present. Diagrams were made of the relative positions of follicles and corpora lutea in the ovaries and were used to monitor changes in ovarian structures on subsequent days. Videotapes of ultrasound examinations were reviewed on an Electrohome video monitor with a $22 \times 28 \mathrm{~cm}$ screen. Diameters of follicles $\geq 5 \mathrm{~mm}$ and the length and width of corpora lutea were measured to the nearest $0.5 \mathrm{~mm}$ against the scale recorded from the ultrasound unit. Diameters of follicles that were not spherical were estimated by averaging the longest and shortest diameters. New diagrams of the ovaries were made and compared to those made at the time of ultrasound examinations.

Validation of ultrasonic measurements of follicular diameter. Ovaries obtained from a slaughterhouse were placed in a water bath $\left(22^{\circ} \mathrm{C}\right)$ and the diameters of 23 follicles were determined by ultrasonography. These follicles were then dissected from the ovaries, trimmed of stromal tissue and their diameters were measured. Results of the two methods were compared.

Experimental protocol. Holstein heifers that had normal and regular oestrous cycles were selected at random from our herd. Two groups of heifers (3/group) were given a single i.m. injection of $25 \mathrm{mg}$ PGF-2 $\alpha$ (Lutalyse, Upjohn Co., Kalamazoo, MI, U.S.A.) between Days 12 and 15 of the oestrous cycle (Day $0=$ oestrus) to induce regression of the corpus luteum. Ultrasound examinations were performed daily from the day of PGF- $2 \alpha$ injection through ovulation. In the first group of heifers examinations were at $0,24,56,79$ and $103 \mathrm{~h}$ after PGF-2 $\alpha$ and in the second group at 0,8 , 24, 48, 72 and $96 \mathrm{~h}$ after PGF-2 $\alpha$. Animals were observed twice daily for oestrous behaviour. Heifers in another group $(\mathrm{N}=5)$ were examined by ultrasound each morning from Day 14 or 15 of the oestrous cycle through ovulation. Blood samples were collected by jugular puncture twice daily and concentrations of progesterone in plasma were measured by radioimmunoassay to determine when luteolysis occurred. The progesterone radioimmunoassay (Beal, Milvae \& Hansel, 1980) is highly specific with a sensitivity of $16 \mathrm{pg} /$ tube, an extraction efficiency of $84 \cdot 3 \pm 0 \cdot 8 \%$ (mean \pm s.e.m.; $n=50$; values not corrected for recovery), and mean intra- and inter-assay coefficients of variation ( 2 assays) of 9.5 and $15 \%$, respectively. Heifers were examined by rectal palpation during the mid-luteal phase of the subsequent oestrous cycle to confirm that a corpus luteum was present in the same ovary from which ovulation occurred. 


\section{Results}

\section{Validation of ultrasonic measurements of follicular diameter}

There was a linear relationship between the diameters of follicles measured by ultrasonography and the diameters of the same follicles measured after dissection from the ovaries (Fig. 1). The regression equation is $y=1.70+1.09 x$ where $y=$ follicle diameter $(\mathrm{mm})$ after dissection from the ovary and $x=$ follicle diameter by ultrasonography $(r=0.98, n=23, P<0.001)$. Diameters of dissected follicles were consistently $2-3 \mathrm{~mm}$ larger than the diameters determined by ultrasonography. This difference is to be expected since only the antral cavity of the follicle is visible by ultrasonography.

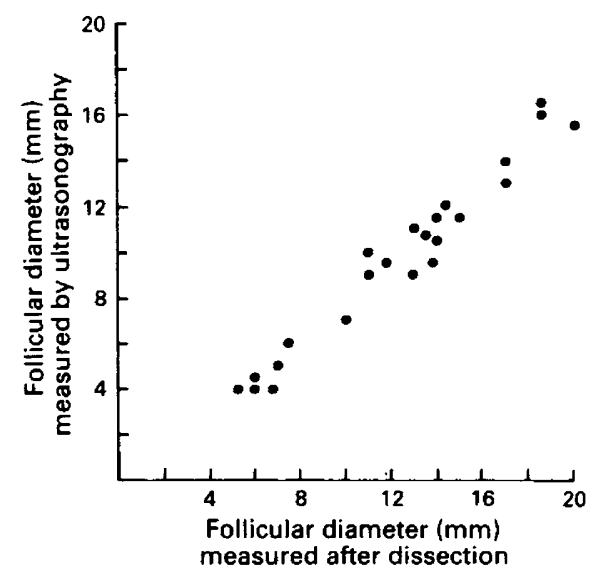

Fig. 1. Relationship between the diameters of follicles $(\mathrm{N}=23)$ measured by ultrasonography of ovaries in a water bath and the diameters of the same follicles measured after dissection from the ovaries.

\section{Ultrasound images of ovaries}

Enlargement of an ovulatory follicle and regression of a non-ovulatory follicle in one ovary of a heifer undergoing spontaneous luteolysis are shown in Fig. 2. Ovulation was detected by the sudden disappearance of a large follicle $>10 \mathrm{~mm}$ which had been present in the ovaries for several days. Follicles as small as $2 \mathrm{~mm}$ were visible by ultrasound but were difficult to follow on subsequent days and to relate spatially to other structures in the ovary. Measurements were therefore restricted to follicles $\geq 5 \mathrm{~mm}$ which could be followed for at least 2 consecutive days.

\section{Comparison of follicle dynamics in heifers undergoing spontaneous and PGF-2 $\alpha$-induced luteolysis}

Growth of ovulatory follicles. Oestrus occurred on the 3rd day after injection of PGF- $2 \alpha$ and between Day 19 and 26 of the oestrous cycle in heifers undergoing spontaneous luteolysis. The dynamics of preovulatory follicular growth during the 3 days before oestrus were similar in PGF-2 $\alpha$-treated and untreated heifers. Mean diameters of ovulatory follicles on each day were not different between groups $(P>0.05$, two-way analysis of variance). On each day there was a wide range in the sizes of ovulatory follicles, as shown in Fig. 3. The growth rates of ovulatory follicles varied amongst heifers; mean increases $(\mathrm{mm} / 24 \mathrm{~h} \pm$ s.d.) in the diameters of ovulatory follicles at 3 , 

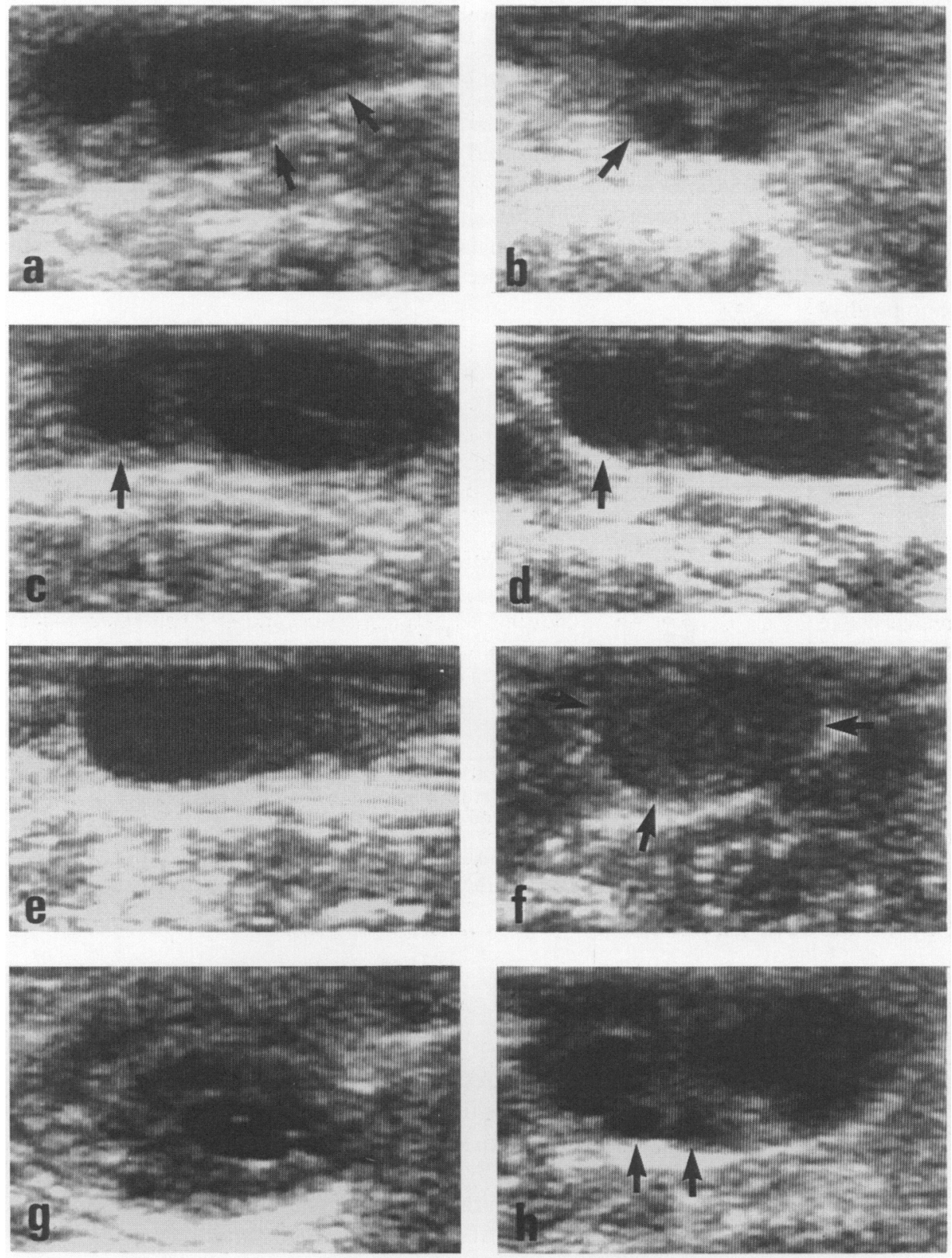

Fig. 2. Examples of ultrasound images of ovaries ( $\times 1 \cdot 2$ actual size). (a-f) Growth of the ovulatory follicle and regression of non-ovulatory follicles are shown in an ovary of a heifer (No. 32) undergoing spontaneous luteolysis.

(a) At 10 days before oestrus; the corpus luteum is indicated by arrows and a non-ovulatory follicle $10.5 \mathrm{~mm}$ in diameter is to the left.

(b) At 7 days before oestrus; the arrow points to the ovulatory follicle $(5.5 \mathrm{~mm})$ which is positioned below the regressing non-ovulatory follicle $(7 \mathrm{~mm})$ seen in (a) and to the left of another non-ovulatory follicle $(3 \mathrm{~mm})$. The corpus luteum is present on the ovary but is not visible in this plane of view.

(c and d) At 5 and 3 days before oestrus; the ovulatory follicle (indicated by arrows) grew 


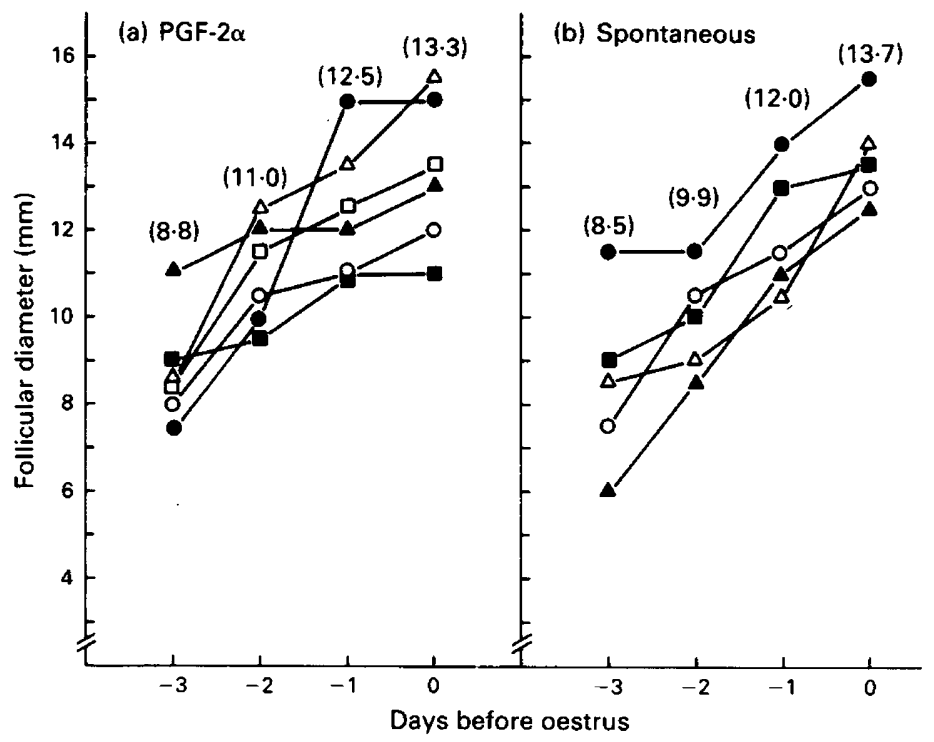

Fig. 3. Growth of individual ovulatory follicles during the 3 days before oestrus in 6 heifers treated with PGF- $2 \alpha$ on Day -3 to induce luteal regression (a) and in 5 heifers undergoing spontaneous luteolysis (b). Different symbols are used for each heifer. Numbers in parentheses are the mean diameters ( $\mathrm{mm}$ ) of follicles on each of the 3 days before oestrus.

2 and 1 day before oestrus were $2 \cdot 3 \pm 1 \cdot 3,1 \cdot 5 \pm 1 \cdot 8$ and $0 \cdot 8 \pm 0 \cdot 8$, respectively in PGF-2 $\alpha$-treated heifers and $1.4 \pm 1 \cdot 3,2 \cdot 1 \pm 0.8$ and $1.7 \pm 1 \cdot 1$, respectively in heifers undergoing spontaneous luteolysis. In the 3 heifers that were examined by ultrasound at $8 \mathrm{~h}$ after injection of PGF-2 $\alpha$, the size of the ovulatory follicle had increased in only one heifer (by $0.5 \mathrm{~mm}$; data not shown). The ovulatory follicle was present in the ovary ipsilateral to the corpus luteum in 4 of 6 heifers treated with PGF-2 $\alpha$ and 3 of 5 heifers undergoing spontaneous luteolysis.

Regression of non-ovulatory follicles. All PGF-2 $\alpha$-treated and untreated heifers had at least one non-ovulatory follicle $\geq 5 \mathrm{~mm}$ present in the ovaries during the 3 days before oestrus. Nonovulatory follicles were present in the ovary ipsilateral or contralateral to the ovulatory follicle or on both ovaries. In general, non-ovulatory follicles decreased in size during the 3 days before oestrus and the amount of overlap in the size ranges of ovulatory and non-ovulatory follicles decreased (Fig. 4). However, in one heifer treated with PGF- $2 \alpha$ a non-ovulatory follicle grew from 5 to $10.5 \mathrm{~mm}$ during the 2 days before oestrus, and in 2 untreated heifers large non-ovulatory follicles persisted in the ovaries through the day of oestrus. The proportion of heifers in which the

from 8 to $11.5 \mathrm{~mm}$. The corpus luteum is to the right of the ovulatory follicle. The non-ovulatory follicles shown in (b) are present in the ovary, but are not visible in this plane of view.

(e) At oestrus; the ovulatory follicle is flattened $(11 \times 20 \mathrm{~mm})$, an appearance typical of follicles immediately before ovulation. The corpus luteum has regressed and cannot be distinguished.

(f) At 1 day after oestrus, the ovulatory follicle has disappeared indicating that ovulation occurred. Arrows indicate the outline of the ovary.

(g) A corpus luteum with an elliptical central cavity surrounded by luteal tissue.

(h) Typical small follicles $(2 \cdot 5-3.5 \mathrm{~mm})$ visible with ultrasound are indicated with arrows. 
ovulatory follicle was the largest follicle present in the ovaries increased during the 3 days before oestrus: $3 / 6,5 / 6,6 / 6$ and $6 / 6$ in PGF-2 $\alpha$-treated heifers and $2 / 5,3 / 5,3 / 5$ and $5 / 5$ in untreated heifers at $-3,-2,-1$ and 0 days from oestrus, respectively. In all heifers the ovulatory follicle was one of the 2 largest follicles present in the ovaries during all 3 days before oestrus.

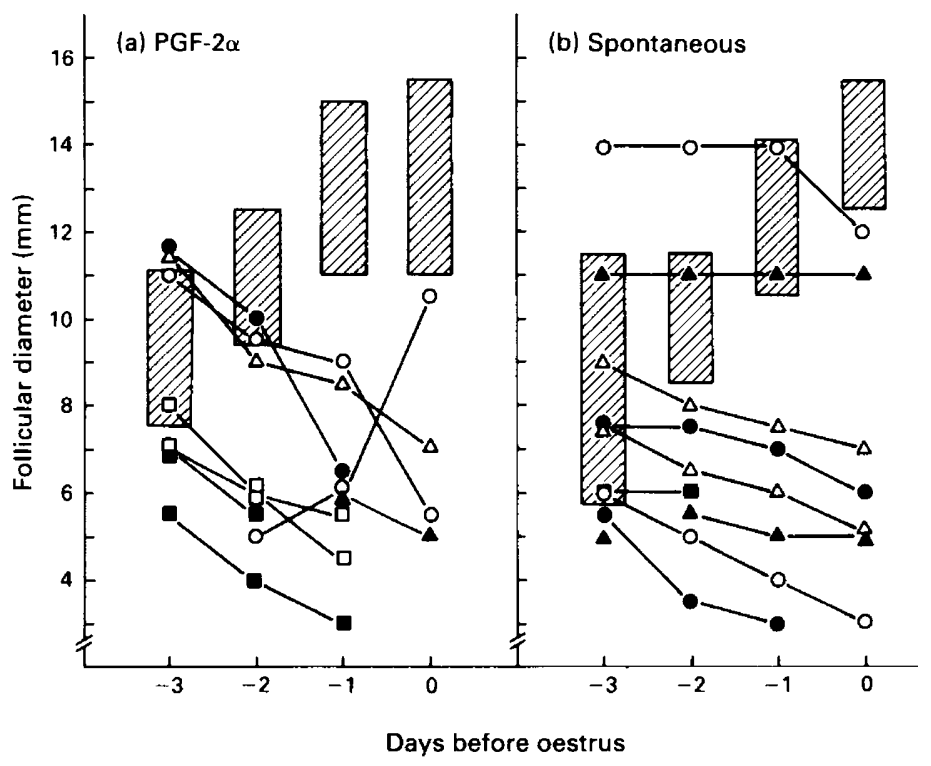

Fig. 4. Growth and regression of individual non-ovulatory follicles during the 3 days before oestrus in heifers treated with PGF- $2 \alpha$ on Day -3 to induce luteal regression (a), and in heifers undergoing spontaneous luteolysis (b). Different symbols are used for each heifer and are the same as symbols used in Fig. 3. For comparison, the shaded bars indicate the size ranges of the ovulatory follicles on each day before oestrus (diameters shown individually in Fig. 3). A symbol standing alone refers to a follicle which was detected by ultrasonography on only 1 day during the 3 days before oestrus.

Follicle dynamics associated with spontaneous regression of the corpus luteum

In 4 of the 5 heifers undergoing spontaneous luteolysis (Nos 267, 25, 105, 32) plasma concentrations of progesterone decreased below $1 \mathrm{ng} / \mathrm{ml}$ by 2 days before oestrus and progressive growth of ovulatory follicles began before or coincident with the decrease in plasma progesterone (Fig. 5). In another heifer (No. 29) plasma concentrations of progesterone decreased below $1 \mathrm{ng} / \mathrm{ml}$ by -4 days before oestrus and the follicular phase was therefore relatively long. In this heifer, the ovulatory follicle was not detected until -3 days before oestrus and was relatively small $(6 \mathrm{~mm})$ compared to the ovulatory follicles in other heifers $(7.5-11.5 \mathrm{~mm})$. No non-ovulatory follicles increased in size during the 3 days before oestrus when ovulatory follicles were growing.

\section{Ultrasonography of corpora lutea}

Corpora lutea were generally oblong in shape (Fig. 2) and measurements were made at the widest and longest points. Since the boundaries between luteal tissue and ovarian stroma became 


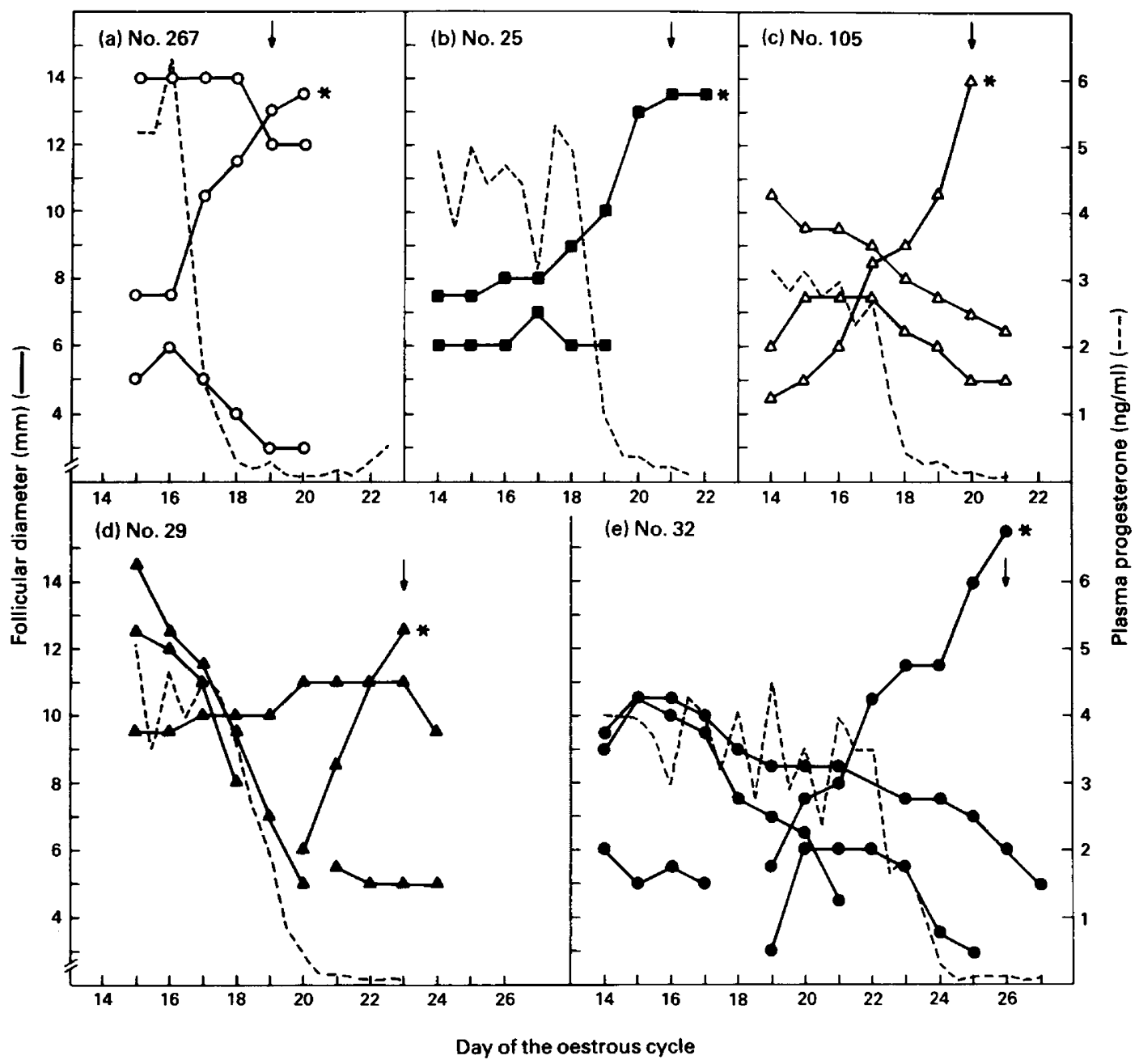

Fig. 5. Growth and regression of ovulatory and non-ovulatory follicles (solid lines) and changes in plasma concentrations of progesterone (broken lines) from Day 14 or 15 of the oestrous cycle to ovulation in each of 5 heifers undergoing spontaneous luteolysis. Ovulatory follicles are marked with asterisks. The day of oestrus in each heifer is indicated by an arrow. The symbols used for each heifer are the same as those used in Figs 3 and 4.

more difficult to discern as corpora lutea regressed, measurements of corpora lutea were made daily until -1 day before oestrus in heifers treated with PGF- $2 \alpha$ and until -2 days before oestrus in heifers undergoing spontaneous luteolysis. In heifers treated with PGF-2 $\alpha$, the size of corpora lutea (width $\times$ length; mean \pm s.d.) decreased from $16.5 \pm 1.9 \times 26.0 \pm 1.8 \mathrm{~mm}$ before PGF- $2 \alpha$ to $13.7 \pm 2.9 \times 22.3 \mathrm{~mm}$ and $12.2 \pm 3.1 \times 20.0 \pm 2.8 \mathrm{~mm}$ at -2 and -1 days from oestrus, respectively. In heifers undergoing spontaneous luteolysis, the size of corpora lutea decreased from $16.8 \pm 2.8 \times 25.8 \pm 2.6 \mathrm{~mm}$ on Day 15 of the cycle to $12.4 \pm 3.2 \times 20.4 \pm 3.9 \mathrm{~mm}$ at -2 days from oestrus. Decreases in the sizes of corpora lutea in each heifer were coincident with decreases in plasma concentrations of progesterone (Fig. 5). In one heifer treated with PGF-2 $\alpha$ and in 2 untreated heifers corpora lutea contained inner cavities (Fig. 2). Plasma concentrations of progesterone in these heifers were within the normal range (Nos 267 and 29; Fig. 5). 


\section{Discussion}

Daily examination of the ovaries by ultrasonography allowed us to monitor growth, ovulation or regression of individual ovarian follicles with diameters $\geq 5 \mathrm{~mm}$. An individual follicle was identified by its position in the ovary and its spatial relationship to other follicles and/or the corpus luteum. Review of videotapes of ultrasound examinations ensured that individual follicles were accurately identified. Previous studies on follicular dynamics in cattle have involved morphological, histological and biochemical characterization of the populations of follicles present on ovaries obtained at various stages of the oestrous cycle (Rajakoski, 1960; Choudary, Gier \& Marion, 1968; Ireland \& Roche, 1983b; Moor, Kruip \& Green, 1984). Ginther \& Pierson (1984) used ultrasonography to characterize populations of follicles of various sizes and to determine the mean diameters of the largest and second largest follicles present in the ovaries throughout the oestrous cycle in heifers, but sequential changes in the sizes of individual ovulatory and non-ovulatory follicles were not reported.

Follicle dynamics during the 3 days before oestrus were similar in PGF- $2 \alpha$-treated and untreated heifers in that (1) the mean diameters of ovulatory follicles on each day did not differ between groups, (2) there was considerable variability among heifers in the growth rates of ovulatory follicles, and (3) the proportion of non-ovulatory follicles within the size ranges of ovulatory follicles progressively decreased. Each of these findings is consistent with results of experiments with sheep in which individual follicles were labelled with ink and then followed at subsequent laparotomies (Driancourt \& Cahill, 1984).

Matton et al. (1981) demonstrated that the occurrence of oestrus was not delayed after destruction of all follicles $>5 \mathrm{~mm}$ by electrocautery on Day 18 of the cycle, indicating that follicles were capable of growing from $<5 \mathrm{~mm}$ to ovulatory size within several days. In contrast, results of the present experiments indicate that ovulatory follicles developed from follicles that were between 6 and $11.5 \mathrm{~mm}$ in diameter at -3 days from oestrus. The differences between these studies emphasize the fact that there is considerable variability in the sizes of follicles which can be selected for preovulatory follicular growth in heifers.

The fact that the ovulatory follicle can develop from follicles of different sizes might explain how at least one follicle in the ovaries during the luteal phase of the cycle is capable of ovulating within several days after PGF-2 $\alpha$-induced luteolysis. In the present study each heifer undergoing spontaneous luteolysis had at least one follicle in the ovaries at Day 15 of the cycle which was within the size range $(7.5-11 \mathrm{~mm})$ of ovulatory follicles in PGF-2 $\alpha$-treated heifers at 3 days before oestrus. In 2 heifers (Nos 267 and 25) these follicles ovulated but in 3 heifers (Nos 105, 29 and 32) these follicles regressed and a smaller follicle grew and ovulated (Fig. 5). Therefore, many follicles may have the potential to become ovulatory if they are at an appropriate stage in their development when luteolysis occurs.

In general, non-ovulatory follicles decreased in size or failed to grow during the 3 days before oestrus when preovulatory follicles were growing. These results support the idea that the large or dominant follicle can inhibit the growth of smaller follicles as suggested by studies with heifers (Matton et al., 1981), sheep (Bhérer, Dufour \& Matton, 1976) and monkeys (Goodman, Nixon \& Hodgen, 1979; DiZerega \& Hodgen, 1980).

During the 3 days before oestrus, the number of non-ovulatory follicles within the size ranges of ovulatory follicles progressively decreased. However, in some heifers large non-ovulatory follicles persisted in the ovaries until the day of oestrus. These results are consistent with reports that there are usually 2 large $(>6 \mathrm{~mm})$ follicles present in the ovaries of heifers after spontaneous or PGF-2 $\alpha$-induced luteolysis, one that is healthy, contains large amounts of oestrogen in the follicular fluid ('oestrogen active') and is most likely to be the ovulatory follicle, and one that is atretic and contains more androgen and progestagen than oestrogen in the follicular fluid ('oestrogen inactive'; Ireland \& Roche, 1982, 1983a).

Dufour et al. (1972) reported that the largest follicle in the ovaries during the 3 days before 
oestrus was the one that ovulated in 4 out of 4 heifers. In the present study this was true at -3 days before oestrus in 2 of 5 heifers undergoing spontaneous luteolysis and in 3 of 6 heifers treated with PGF-2 $\alpha$. At -2 and -1 day from oestrus the number of heifers in which the ovulatory follicle was the largest follicle increased and on the day of oestrus the ovulatory follicle was the largest follicle in all heifers. These results suggest that size alone cannot predict which follicle will ovulate except on the day of oestrus.

Ultrasonography may be a useful technique for monitoring luteal regression since decreases in the size of corpora lutea and in plasma progesterone occurred concomitantly. Corpora lutea in 3 of 11 heifers contained inner cavities, but plasma concentrations of progesterone in these heifers were normal. Corpora lutea with inner cavities have been detected with ultrasonography in horses (Pierson \& Ginther, 1985) and cattle (Reeves et al., 1984; Pierson \& Ginther, 1984) and are not thought to be detrimental to reproductive function (Hammond, 1927).

In summary, the dynamics of follicular growth and regression during the 3 days before oestrus were similar in heifers undergoing spontaneous and PGF- $2 \alpha$-induced luteolysis. Although the follicle destined to ovulate could not be predicted by its size alone, it was one of the 2 largest follicles in the ovaries during the 3 days before oestrus.

We thank Dr J. R. Stouffer for advice on ultrasound procedures, Dr R. B. Hillman for use of the ultrasound unit, and R. G. Cowan for photography supported by NIH grant HD14584.

\section{References}

Beal, W.E., Milvae, R.A. \& Hansel, W. (1980) Oestrous cycle length and plasma progesterone concentrations following administration of prostaglandin F-2 $\alpha$ early in the bovine oestrous cycle. J. Reprod. Fert. 59, 393-396.

Bhérer, J., Dufour, J. \& Matton, P. (1976) Destinée des deux plus gros follicules des ovaries de brebis à la suite de la destruction du plus gros follicule et/ou de l'enlèvement du corps jaune à deux moments du cycle. Can. J. Physiol. Pharmacol. 54, 7-11.

Choudary, J.B., Gier, H.T. \& Marion, G.B. (1968) Cyclic changes in bovine vesicular follicles. J. Anim. Sci. 27, $468-474$.

DiZerega, G.S. \& Hodgen, G.D. (1980) The primate ovarian cycle: suppression of human menopausal gonadotropin-induced follicular growth in the presence of the dominant follicle. J. clin. Endocr. Metab. 50, 819-825.

Driancourt, M.A. \& Cahill, L.P. (1984) Preovulatory follicular events in sheep. J. Reprod. Fert. 71, 205-211.

Dufour, J., Whitmore, H.L., Ginther, O.J. \& Casida, L.E. (1972) Identification of the ovulating follicle by its size on different days of the estrous cycle in heifers. $J$. Anim. Sci. 34, 85-87.

Ginther, O.J. \& Pierson, R.A. (1984) Ultrasonic anatomy of equine ovaries. Theriogenology 21, 471-483.

Goodman, A.L., Nixon, W.E. \& Hodgen, G.D. (1979) Regulation of folliculogenesis in the cyclic rhesus monkey. In Ovarian Follicular Development and Function, pp. 29-37. Eds A. R. Midgley, Jr \& W. A. Sadler. Raven Press, New York.

Hammond, J. (1927) Reproduction in the Cow. Cambridge University Press.

Ireland, J. \& Roche, J.F. (1982) Development of antral follicles in cattle after prostaglandin-induced luteolysis: changes in serum hormones, steroids in follicular fluid, and gonadotropin receptors. Endocrinology 111, 2077-2086.

Ireland, J.J. \& Roche, J.F. (1983a) Growth and differentiation of large antral follicles after spontaneous luteolysis in heifers: changes in concentrations of hormones in follicular fluid and specific binding of gonadotropins to follicles. J. Anim. Sci. 57, 157-167.

Ireland, J.J. \& Roche, J.F. (1983b) Development of nonovulatory antral follicles in heifers: changes in steroids in follicular fluid and receptors for gonadotropins. Endocrinology 112, 150-156.

Matton, P., Adelakoun, V., Couture, Y. \& Dufour, J.J. (1981) Growth and replacement of the bovine ovarian follicles during the estrous cycle. J. Anim. Sci. 52, 813-820.

Moor, R.M., Kruip, Th.A.M. \& Green, D. (1984) Intraovarian control of folliculogenesis: limits to superovulation? Theriogenology 21, 103-115.

Palmer, E. \& Driancourt, M.A. (1980) Use of ulrasonic echography in equine gynecology. Theriogenology 13, 203-216.

Pierson, R.A. \& Ginther, O.J. (1984) Ultrasonography of the bovine ovary. Theriogenology 21, 495-504.

Pierson, R.A. \& Ginther, O.J. (1985) Ultrasonic evaluation of the corpus luteum of the mare. Theriogenology 23, 795-806.

Rajakoski, E. (1960) The ovarian follicular system in sexually mature heifers with special reference to seasonal, cyclical, and left-right variations. Acta endocr., Copenh., Suppl. 52, 1-68.

Reeves, J.J., Rantanen, N.W. \& Hauser, M. (1984) Transrectal real-time ultrasound scanning of the cow reproductive tract. Theriogenology 21, 485-494.

Received 3 September 1985 